\title{
Divertículo esofágico de tercio medio: Una causa infrecuente de disfagia
}

\author{
Middle third esophageal diverticulum: An infrequent cause of dysphagia \\ Julio César Moreno-Alfonso ${ }^{1} \mathbb{D}$, Inés Eguaras-Córdoba ${ }^{\mathbb{D}}$, María Concepción Yárnoz-Irazábal ${ }^{3} \mathbb{D}$, \\ María del Coro Miranda-Murua ${ }^{4} \mathbb{D}$
}

1 Médico y Cirujano General, Fundación Universitaria Juan N. Corpas; residente de Cirugía pediátrica, Complejo Hospitalario de Navarra, Pamplona, España.

2 MD, especialista en Cirugía general, Universidad de Navarra; residente de Cirugía general y del Aparato digestivo, Complejo Hospitalario de Navarra, Pamplona, España.

3 MD, especialista en Cirugía general y del Aparato digestivo; facultativo, Unidad de Cirugía esofagogástrica y bariátrica, Complejo Hospitalario de Navarra, Pamplona, España. Profesora asociada de anatomía y embriología humana, Universidad Pública de Navarra. Pamplona, España.

4 MD, especialista en Cirugía general y del Aparato digestivo; jefa, Unidad de Cirugía esofagogástrica y bariátrica, Complejo Hospitalario de Navarra, Pamplona, España.

Mujer de 72 años de edad, con cuadro clínico de un año de disfagia y atragantamiento con alimentos sólidos, que había requerido tratamiento endoscópico. Se realiza endoscopia de vías digestivas altas que documenta un divertículo esofágico en tercio medio, y manometría esofágica de alta resolución, sin trastorno motor. El esofagograma (figura i) y la tomografía computarizada de tórax (figura 2) muestran un divertículo en tercio medio de esófago, lateral derecho, de 7 $\mathrm{cm}$ de diámetro y base de $2.5 \mathrm{~cm}$ de diámetro. De manera programada se lleva a cabo diverticulec- tomía esofágica por toracoscopia, en decúbito prono (figura 3), sin complicaciones.

\section{Discusión}

Los divertículos esofágicos son una patología infrecuente, con una prevalencia de $0,06-4 \%{ }^{\mathrm{I}-4}$. Suelen ser asintomáticos, pero en caso contrario, el síntoma más frecuente es la disfagia ${ }^{2-4}$. Los divertículos esofágicos del tercio medio se forman por mecanismo de tracción, y se asocian a procesos inflamatorios crónicos del mediastino, fibrosis y trastornos motores del esófago, en un

Palabras clave: esófago; divertículo esofágico; trastornos de la motilidad esofágica; endoscopía del sistema digestivo; diagnóstico por imagen; cirugía torácica asistida por video.

Key words: esophagus; diverticulum, esophageal; esophageal motility disorders; endoscopy, digestive system; diagnostic imaging; thoracic surgery, video-assisted.

Fecha de recibido: 11/02/2020 - Fecha de aceptación: 14/02/2020

Correspondencia: Julio César Moreno A., Carrera 75 \# 23B - 34, Bogotá, D.C., Colombia.

Teléfono: +57 3118572978

Correo electrónico: juliomoreno.md@gmail.com

Citar como: Moreno-Alfonso JC, Eguaras-Córdoba I, Yárnoz-Irazábal MC, Miranda-Murua MC. Divertículo esofágico de tercio medio: Una causa infrecuente de disfagia. Rev Colomb Cir. 2020;35:498-9. https://doi.org/10.30944/20117582.562

Este es un artículo de acceso abierto bajo una Licencia Creative Commons - BY-NC-ND https://creativecommons.org/licenses/by-ncnd/4.0/deed.es 


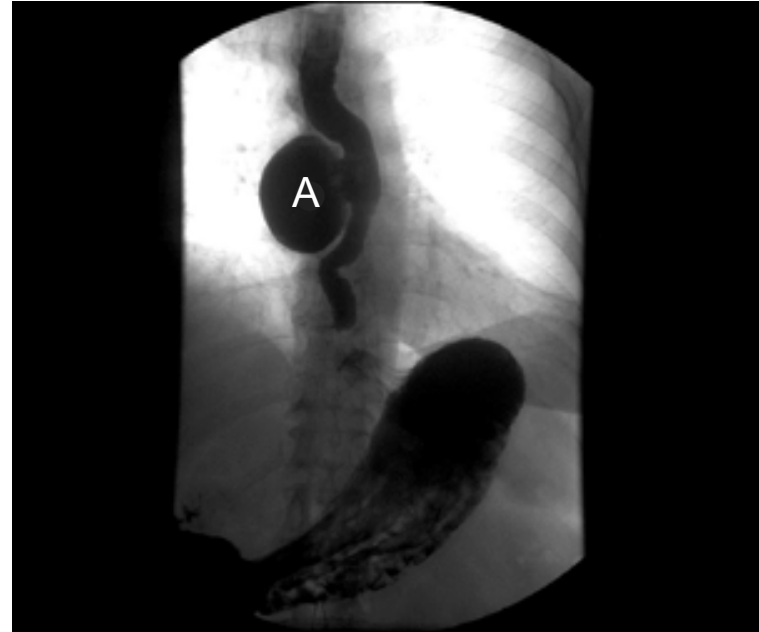

Figura 1. Divertículo esofágico de tercio medio, lateral derecho $(A)$.

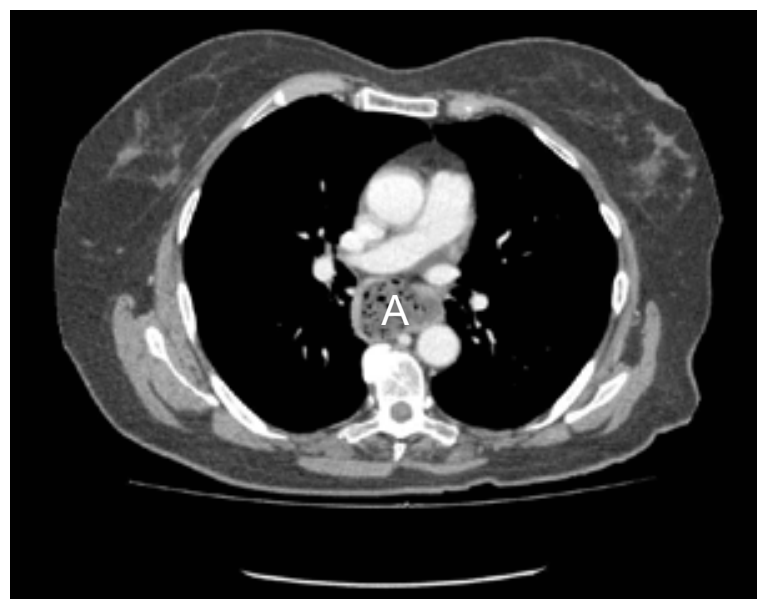

Figura 2. Divertículo esofágico de tercio medio con restos alimentarios en su interior (A).

$90 \%$ de los casos; sin embargo, se desconoce si el trastorno motor es primario o secundario a la presencia del divertículo ${ }^{1,2,4}$. Puesto que suelen ser asintomáticos, el diagnóstico es habitualmente incidental mediante esofagograma u otras pruebas radiológicas o endoscópicas, y no precisan tratamiento ${ }^{\mathrm{I}-4}$. No obstante, ante la presencia de síntomas, el tratamiento de elección es la resección quirúrgica por toracoscopia o toracotomía ${ }^{2-4}$.

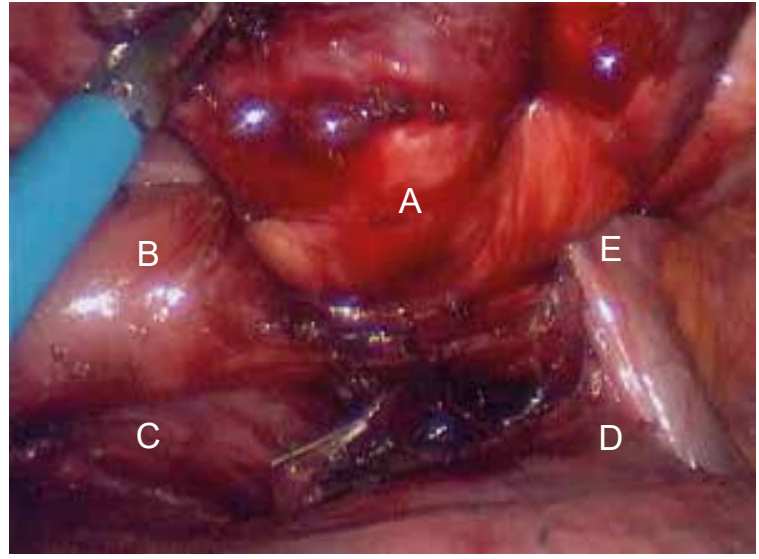

Figura 3. Divertículo (A) y esófago distal (B), en relación anatómica con las venas pulmonares derechas $(\mathrm{C})$, bronquio principal derecho (D) y cayado de la vena ácigos $(E)$.

\section{Cumplimiento de normas éticas}

Consentimiento informado: Esta publicación es una revisión de historia clínica retrospectiva, y las imágenes no permiten identificar la paciente, por lo que no hay necesidad de un consentimiento informado.

Declaración de conflicto de intereses: los autores declaran que no tienen conflicto de intereses.

Fuentes de financiación: Recursos propios de los autores.

\section{Referencias}

I. Sato H, Takeuchi M, Hashimoto S, Mizuno KI, Furuwaka K, Sato A, et al. Esophageal diverticulum: New perspectives in the era of minimally invasive endoscopic treatment. World J Gastroenterol. 2019;25:I457-64.

https://doi.org/IO.3748/wjg.v25.iI2.I457

2. Martínez-Marín JD. Divertículo gigante del esófago torácico. Rev Col Gastroenterol. 2008;23:387-89.

3. Whittle C, Schiappacasse G, Leal E, Franz G, Hasson D, Maldonado I, et al. Imágenes en divertículos del tubo digestivo: Localizaciones infrecuentes. Serie de casos. Rev Chil Radiol. 20I8;24:67-78.

4. Herbella FA, Patti MG. Modern pathophysiology and treatment of esophageal diverticula. Arch Surg. 2012;397:29-35.

https://doi.org/IO.IOO7/s00423-0II-0843-2 